\title{
Interpretación bíblica en el mundo posmoderno: desafíos, peligros y confilictos en la hermenéutica adventista actual
}




\section{Benjamín Rojas \\ Universidad Peruana Unión}

benjamin@upeu.edu.pe 


\section{RESUMEN}

"Interpretación bíblica en el mundo posmoderno: desafíos, peligros y conflictos en la hermenéutica adventista actual" El estudio aborda una problemática compleja, actual y polémica, que está directamente relacionada con el quehacer hermenéutico en el seno de la Iglesia Adventista del Séptimo Día. La llegada de la modernidad y también de la posmodernidad trajeron innovaciones filosóficas que han influenciado todo quehacer humano, entre ellas, la interpretación de la Biblia. En la primera parte, el autor expone, apoyado en diversos autores, la realidad axiomática y la metodología sobre la cual se desarrolla el quehacer hermenéutico entre los más importantes círculos bíblico-académicos. En la segunda parte, se presenta los desafíos, peligros y conflictos en la hermenéutica bíblica adventista, basándose en documentos escritos por autores adventistas. Finalmente, se expone propuestas que podrían ayudar a solucionar la problemática hermenéutica dentro de la Iglesia Adventista del Séptimo Día, manteniéndola como una iglesia fundamentada en una filosofía bíblica y no en la filosofía del momento.

Palabras claves: hermenéutica, interpretación, axiomas, posmodernismo, hermenéutica adventista.

\section{SUMMARY}

"Biblical Interpretation in Postmodern World: Challenges, Dangers and Conflicts in Today's Adventist Hermeneutics" - The study addresses a complex and controversial issue today, which is directly related to the hermeneutical task within the Seventh-day Adventist Church. The advent of modernity and postmodernity brought philosophical innovations that have influenced all human endeavors, including the interpretation of the Bible. In the first part, the author presents, supported by several authors, the axiomatic reality and the methodology on which the hermeneutical task develops among the most important biblical-academic circles. In the second part, the challenges, dangers and conflicts in Adventist biblical hermeneutics, based on documents written by Adventist authors, is presented. Finally, some proposals that could help solve the hermeneutic problems within the Seventh-day Adventist Church are presented, keeping it as a church founded on a biblical philosophy and not in the mere philosophy of time.

Keywords: hermeneutic, interpretation, axioms, posmodernism, adventist hermeneutic 


\section{INTERPRETACIÓN BÍBLICA EN EL MUNDO POSMODERNO: DESAFÍOS, PELIGROS Y CONFLICTOS EN LA HERMENÉUTICA ADVENTISTA ACTUAL}

\section{Introducción}

La Sagrada Escritura (SE), ${ }_{1}^{1}$ debe ser interpretada. $\mathrm{Al}$ respecto, Gibbs, McGhee y Teague, señalan que la historia de la interpretación bíblica, debe recordar al estudioso de la SE que siempre existió un conflicto entre aquellos que la reconocen como Palabra de Dios autoritativa e incuestionable y aquellos que no. ${ }^{2}$ Hoy este debate se ha reiniciado, pues como Greene-McCreight ya reconocía en el 2005, durante los últimos 20 años la discusión en el campo de la interpretación bíblica ha girado en torno a los muy antiguos postulados sostenidos por la escuela de Alejandría y Antioquía. ${ }^{3}$

1Se usará en este documento la sigla "SE" para referirse a la Sagrada Escritura y se deberá entender por ella, el conjunto de los 66 libros que conforman la Santa Biblia.

${ }^{2}$ Carl Gibbs, Quentin McGhee, y Willard Teague, Introducción a la hermenéutica: cómo interpretar la Biblia, ed. Maximiliano Gallardo, trad. José Silva Delgado, 1ra ed. (Springfield, MO: Global University, 2007), 29-45. Por su parte Trevijano reconoce que en el pasado se leía y escuchaba la palabra de Dios sin discutir sobre ella, y reconociéndola como palabra autoritativa de Dios, sin embargo, él se equivoca al afirmar que "no hay que caer en fundamentalismos bíblicos, menos aún en fundamentalismos patrísticos", ya que para él una parte del trabajo exegético antiguo puede considerarse caduco. Véase, Ramón Trevijano Etcheverría, La Biblia en el cristianismo antiguo (Navarra: Editorial Verbo Divino, 2001), 26.

${ }^{3}$ Kathryn Greene-McCreight, "Interpretation, History of", en Dictionary for Theological Interpretation of the Bible, ed. Kevin J. Vanhoozer et al.(London; Grand Rapids, MI.: Baker Academic, 2005), 331. 
Sin embargo, los principios que guiaron al verdadero cristianismo de todos los tiempos en su acercamiento a la SE no quedaron en el olvido, un ejemplo de ello es el principio denominado "centralidad de la Biblia como palabra revelada de Dios", empleado aun antes de la reforma, por los celtas, albigenses, valdenses y lolardos. ${ }^{4}$ También es necesario recordar que durante la reforma y luego de ella, el principio, denominado como sola Scriptura, fue el más importante para la interpretación de la SE. ${ }^{5}$ Empero, también la historia se encargó de registrar que aquellos, que ven a la SE como un texto común, fantasioso, contradictorio, o como la palabra de un dios -en minúscula- que comunica su mensaje en un lenguaje alegórico, figurativo y oscuro, nunca dejaron de existir. ${ }^{6}$

Pero cuando se habla de la interpretación de los textos, se debe reconocer que todo estudio literario, incluyendo los estudios bíblicos, se realizan en base a dos pilares: los métodos hermenéuticos, ${ }^{7}$ y las presupo-

${ }^{4}$ Miguel Ángel Nuñez, La verdad progresiva: Desarrollo histórico de la teología adventista (Lima: Ediciones Fortaleza, 2007), 9-17.

5James Montgomery Boice, O Alicerce da Autoridade Bíblica (São Paulo: Sociedade Religiosa Edições Vida Nova, 1982), 9-12.

${ }^{6}$ Esta realidad queda expuesta en la clásica obra de Farrar y más recientemente en el trabajo de Gonzales, Véase, Frederic W. Farrar, History of Interpretation (London: Macmillan and Co., 1886), 3-553; Justo L. González, Historia del pensamiento cristiano (Barcelona: Editorial Clie, 2010), 41-968.

${ }^{7}$ Algunos métodos hermenéuticos son: El método socioretórico de interpretación propuesto por Robbins, Corley explica el Método histórico gramatical (MHG) y también diversas formas inductivas de estudiar la Biblia, como el sintético, el analítico, el devocional entre otros. Véase, Bruce Corley, Steve Lemke, y Grant Lovejoy, Biblical Hermeneutics: A Comprehensive 
siciones. ${ }^{8}$ Estos pilares se han ido renovando e incrementando conforme ha transcurrido el tiempo; ${ }^{9}$ sin embargo, durante los dos siglos pasados sus cambios han sido mucho más dramáticos. ${ }^{10}$ Como lo señalan diversos autores, posiblemente estos cambios se deban al surgimiento del iluminismo, ${ }^{11}$ de las "tendencias racionalistas, secularistas,

Introduction to Interpreting Scripture (Nashville, Tennessee: Broadman and Holman, 1996), 21-53; Vernon K. Robbins, Exploring the Texture of Texts: A Guide to Socio-Rhetorical Interpretations (Valley Forge, PA: Trinity Press International 1996), 1-132.

${ }^{8}$ Graham N. Stanton, "Presuppositions in New Testament Criticism", en New Testament Interpretation: Essays on Principles and Methods, ed. I. Howard Marshall (Eugene, OR: Wipf \& Stock Publishers, 2006), 67.

${ }^{9}$ Tanto los métodos como las presuposiciones han cambiado conforme pasa el tiempo, hecho reconocido por Gonzales en la introducción de su importante obra el pensamiento cristiano. González, 35-40. Por su parte, Salguero presenta de forma clara el desarrollo hermenéutico y los cambios que ella ha sufrido en el campo de la interpretación bíblica, Manuel De Tuya y José Salguero, Introducción a la Biblia II: Hermenéutica bíblica, historia de la interpretación de la Biblia, instituciones israelitas, geografía de Palestina (Madrid: Editorial Católica, 1967), 175-277. Fernández, iniciando desde los primeros siglos del cristianismo, aborda el caso específico de Ignacio de Antioquía, Marción, Ptolomeo, Tertuliano, Orígenes y otros. P. Samuel. Fernández E., "Regulæ fidei et rationis: tradición, razón y escritura en los primeros siglos", Teología y Vida 46 (2005) 120.

${ }^{10}$ Sobre los cambios dramáticos que ha sufrido la interpretación bíblica en los últimos siglos y décadas véase William Klein, Craig Blomberg, y Robert Hubbard, Introduction to Biblical Interpretation (Nashville: Thomas Nelson, 2004), 21-28.

${ }^{11}$ Ángel Manuel Rodríguez sostiene que el iluminismo afectó significativamente al proceso de interpretación y comprensión de la SE, él dice que "El rechazo del Iluminismo a cualquier autoridad externa tuvo un impacto profundo sobre la historia de la hermenéutica y en la teología cristiana en general, y resultó en la formulación del método histórico crítico para el estudio de la Escritura". Ángel Manuel Rodríguez, "Hermenéutica contemporánea: cuestiones y problemas", en Entender la palabra: Hermenéutica adventista para el nuevo siglo, ed. Merling Alomía, et al.(Cochabamba: Editorial 
naturalistas y ateas de los cristianos del siglo XIX"12 y de los avances hechos por las ciencias humanas, ${ }^{13}$ entre las cuales, la filosofía es una de las que más impacto ha tenido, ${ }^{14}$ influyendo de forma significativa en el quehacer humano general, en la comprensión del mundo, en la interpretación de los hechos ocurridos en ella, y de forma especial en la

UAB, 2000), 7. Véase también, Bianca Magnino, Iluminismo y cristianismo (Barcelona: Editorial Liturgia Española, 1962), 15.

${ }^{12}$ Enrique Espinoza, "El racionalismo de liberales y fundamentalistas", en Entender la Palabra: hermenéutica adventista para el nuevo siglo, ed. Merling Alomía, et al.(Cochabamba: Editorial UAB, 2000), 138. Knight dice que al respecto: "El liberalismo protestante en la década de 1920 ya se había desembarazado de ideas tan "primitivas" como el nacimiento virginal, la resurrección de Cristo, la expiación sustitutiva, los milagros, la segunda venida, el creacionismo y consecuentemente de una Biblia divinamente inspirada". George R. Knight, La visión apocalíptica y la castración del adventismo: ¿Estamos borrando nuestra relevancia? (Florida: Asociación Publicadora Interamericana, 2009), 19.

${ }^{13}$ Pontificia Comisión Bíblica, "La interpretación de la Biblia en la iglesia", Revista bíblica 56:2 (1994) 3. Este documento oficialmente publicado en la web del vaticano, afirma la influencia filosófica sobre la interpretación bíblica.

${ }^{14}$ Las ideologías que surgieron de filósofos como Aquino (1224/51274), Descartes (1596-1650), Kant (1724 - 1804), Hegel (1770-1831), Marx (1818-1883), Nietzsche (1844-1900), Heidegger (1889-1976), Gadamer (1900-2002), Sartre (1905-1980), Barthes (1915-1980) y Derrida (1930-2004), influyeron definitivamente en los paradigmas humanos y con ello en las presuposiciones hermenéuticas. Véase, Brown Colin, Christianity E Western Thought (Nashville, Tennessee: Broadman \& Holman Publishers, 1990), 19336; Antonin Dalmace Sertillanges, El cristianismo y las filosofías (Madrid: Editorial Gredos, 1966), 44-64; Ludwig Feuerbach, La esencia del cristianismo: Crítica filosófica de la religión (Buenos Aires: Editorial Claridad, 1941), 199283; Hans-Georg Gadamer, Verdad y método: Fundamentos de una hermenéutica filosófica, trad. Ana Agud Aparicio y Rafael de Agapito (Salamanca: Ediciones Sígueme, 1977), 331-584; Samuel Vila, La nada o las estrellas: Una respuesta cristiana a la filosofía existencialista y dialéctico-marxista (Barcelona: Editorial CLIE, 1979), 85-120. 
hermenéutica bíblica. La Pontificia Comisión Bíblica, en el año 1994, ya era consciente de esto, pues en uno de los más importantes documentos elaborados por ella, señala,

La reflexión hermenéutica ha tomado un nuevo impulso con la publicación de los trabajos de Friedrich Schleiermacher, Wilhelm Dilthey y, sobre todo, Martin Heidegger. En las huellas de estos filósofos, pero también apartándose de ellos, otros autores han profundizado la teoría hermenéutica contemporánea y sus aplicaciones a la Escritura. Entre ellos mencionaremos especialmente a Rudolf Bultmann, Hans Georg Gadamer y Paul Ricoeur. ${ }^{15}$

Son probablemente estas corrientes filosóficas las que han originado acercamientos hermenéuticos ${ }^{16}$ modernos, ${ }^{17}$ que al ser aplicados han producido, en el

${ }^{15}$ Pontificia Comisión Bíblica, 29. También véase, Vicente Balaguer, "La cuestión hermenéutica en el documento: Sobre la interpretación de la Biblia en la vida de la iglesia", Scripta Theologica 27:1 (1995 ) 163-77.

${ }^{16}$ Existe una diferencia entre método y acercamiento hermenéutico, se entiende por "método" hermenéutico a un conjunto de procedimientos científicos puestos en acción para explicar los textos; y se habla de "acercamiento" cuando se trata de una búsqueda orientada según un punto de vista particular. Sobre la diferencia entre método y acercamiento véase Javier Quezada del Río, Los hechos de Dios: ¿Qué es la Biblia? Por qué y cómo leerla (México, DF: Editorial de la Universidad Iberoamericana, 2007), 243.

${ }^{17}$ Es la filosofía como praxis, la que ha dado origen a la hermenéutica, pues la capacidad de reflexionar lleva al hombre a buscar una explicación de los hechos que lo rodean. Algunos acercamientos hermenéuticos actuales son mencionados por Quezada del Río: "Acercamiento por los efectos del texto", "Acercamientos psicológicos y psicoanalíticos", "Acercamientos por la antropología cultural", "Acercamiento sociológico". Ibid., 161-246. 
cristianismo, una significativa pérdida de feligreses ${ }^{18}$ (hecho claramente evidenciado en el cristianismo norteamericano), el surgimiento de una mayor variedad de grupos religiosos, ${ }^{19}$ y nuevas teologías, como la teología ecuménica, $^{20}$ la teología de la liberación, ${ }^{21}$ la teología

${ }^{18}$ Knight, 20.

${ }^{19}$ Ramos, luego de haber dedicado más de 25 años de su vida a la enseñanza de religiones comparadas e historia de la iglesia, afirma haber visto a través de esos años "surgir una serie de nuevos movimientos y de organizaciones que aún no se han descrito en diccionarios ni en obras similares y que empiezan a penetrar el mundo de las ideas, así como las creencias de las diferentes feligresías". Nuevo diccionario de religiones denominaciones y sectas, s.v. "Prefacio."

${ }^{20}$ Míguez afirma que al llegar el pensamiento posmoderno surgen los grandes cambios sociales y que "Simultáneamente, menos famosos pero con una visión distinta del problema, fueron surgiendo "teólogos ecuménicos"... Estos fueron marcando un nuevo paso en la forma de hacer teología, donde las tradiciones confesionales no eran determinantes, ni tema del pensar teológico, sino un elemento entre otros en el tratamiento común de los diversos temas. Así, esta teología ecuménica -necesariamente distinta por su concepción y contenido de la teología del ecumenismo- sirve indistintamente en las diferentes confesiones". Néstor O. Míguez, "Nuevo ecumenismo: ¿Nueva iglesia?", Cuadernos de Teología 4:1 (1975) 59. Otros autores que abordan el tema son: Gregory Baum, Ecumenical Theology, 2 vols. (Mahwah, NJ: Paulist Press, 1967), 165-218; Yves Congar y José María Baguñá, Cristianos en diálogo: Aportaciones católicas al ecumenismo (Barcelona: Editorial Estela, 1967), 75-85.

${ }^{21}$ Díaz dice que la teología de la liberación "constituye un enfoque original e innovador dentro de la Teología, la filosofía y la sociología latinoamericana". Luis Gerardo Díaz Núñez, La teología de la liberación latinoamericana a treinta años de su surgimiento: balance y perspectivas (Toluca, México: Universidad Autónoma del Estado de México, 2005), 125. Véase también, Iglesia Católica Sagrada Congregación, Instrucción sobre algunos aspectos de la "Teología de la Liberación" (Lima: Editorial Salesiana, 1984); Atilio René Dupertuis, Liberation Theology a Study in its Soteriology (Barrien Springs, Michigan: Andrews University Press, 1987), 52-99; Gustavo Gutiérrez, Teología de la liberación: perspectivas (Lima: Centro de Estudios y Publicaciones, 1991), 65-434; Francisco Interdonato, Teología latinoamericana: ¿Teología de la liberación? (Bogotá: Ediciones Paulinas, 1978), 9-29; Ronald H. 
queer, ${ }^{22}$ entre otras. Esto justifica a Balaguer cuando luego de analizar el documento "Sobre la interpretación de la Biblia en la vida de la Iglesia afirma que,

Si hay algún lugar espinoso en el debate actual de las ciencias humanas, este lugar es, sin duda alguna, el que se refiere a la cuestión hermenéutica ... Es evidente, [dice Balaguer] que la exégesis bíblica no es ajena al debate -al menos en lo que afecta a la comprensión-; por tanto, parece lógico que la cuestión hermenéutica tenga también su lugar en el reciente Documento de la Pontificia Comisión Bíblica "Sobre la interpretación de la Biblia en la vida de la Iglesia. ${ }^{23}$

Nash, Liberation Theology (Grand Rapids, MI: Baker Book House, 1988), 3-15; Juan Luis Segundo, Teología de la liberación: Respuesta al cardenal Ratzinger (Madrid: Ediciones Cristiandad, 1985), 113-74; Juan José Tamayo-Acosta, Para comprender la teología de la liberación (Navarra: Editorial Verbo Divino, 1989), 98-109.

${ }^{22}$ Musskopf dice que fueron las nuevas teologías, refiriéndose a la teología feminista y a la teología de la liberación, que impulsaron el surgimiento de la teología gay que en sus palabras "propõe uma hermenêutica bíblica... perguntando como homens gays lêem a Bíblia". André Sidnei Musskopf, "A Teologia que sai do Armário: Um depoimento teológico", Impulso 14:34 (2003) 134. "La Teoría queer surgió hacia 1990, cuando Teresa de Lauretis acunó el término. La historia de la sexualidad de Foucault (1978) y las obras de otros postestructuralistas, como Jacques Derrida, han sido fundamentales para la evolución del análisis queer sobre identidad y política. Así pues, son muchos los teóricos queer que utilizan el postestructuralismo". Marla Morris, "El pie zurdo de Dante pone en marcha la teoría queer", en Pensando Queer-Sexualidad, Cultura y Educación, ed. Shirley R. Steinberg y Susan Talburt (Barcelona: Editorial Graó de IRIF, S.L., 2005), 36.

${ }^{23}$ Balaguer, 163. Véase también, José A. Jáuregui, “Biblia y hermenéutica: VII simposio internacional de teología de la Universidad de Navarra", Estudios Eclesiásticos 62:241 (1987) 237,38. Para el material resultante del VII simposio internacional de la teología, véase, José María 


\title{
La hermenéutica bíblica en el mundo
}

\begin{abstract}
Ante todo lo mencionado, la sociedad teológica mundial ha volcado sus esfuerzos para encontrar una forma diligente y respetuosa de aproximarse al texto de la SE, con el objetivo de extraer de ella el verdadero, auténtico y original mensaje de Dios. Teólogos católicos como, Luigi Pecci, Giovanni Pacelli, Karol Wojtyla, ${ }^{24}$ entre otros, reconocieron la problemática hermenéutica al estudiar la SE y promovieron el desarrollo de un método mejor, objetivo claramente expuesto en el documento: "La interpretación de la Biblia en la Iglesia", ${ }^{25}$ elaborado por la Pontificia Comisión Bíblica
\end{abstract}

Casciaro, "Biblia y hermenéutica: VII simposio internacional de teología de la Universidad de Navarra", Colección Teológica 49:1 (1986) 89-101.

${ }^{24}$ Vincenzo Gioacchino Raffaele Luigi Pecci, comúnmente conocido como León XIII redactó la Encíclica Providentissimus en 1893, en la que se aborda el problema hermenéutico. Cincuenta años más tarde, en 1943, Eugenio María Giuseppe Giovanni Pacelli, popularmente conocido como Pio XII publicó la encíclica Divino Afflante, que al igual que su predecesora, abordó el tema de la hermenéutica bíblica. Veintidós años después, en 1965, el Concilio Vaticano II publicó la constitución dogmática Dei Verbum, en la que también se abordó el tema. Bernard Sesboüé y Christoph Theobald, La palabra de la salvación, vol. 4 (Salamanca: Secretariado Trinitario, 1997), 277, 95-97, 403-37.

${ }^{25}$ Documento presentado el 15 de abril de 1993 con motivo de celebrarse el centenario de la encíclica Providentissimus, el documento señala como su objetivo, ". . . considerar seriamente, portanto, os diversos aspectos da situação atual em matéria de interpretação bíblica . . . A Pontifícia Comissão Bíblica deseja indicar os caminhos que convém tomar para chegar a uma interpretação da Bíblia que seja tão fiel quanto possível a seu caráter ao mesmo tempo humano e divino. Ela não pretende tomar aqui posição sobre todas as questões que são feitas a respeito da Bíblia... O que ela quer é examinar os métodos suscetíveis de contribuírem com eficácia a valorizar todas as riquezas contidas nos textos bíblicos, a fim de que a Palavra de Deus possa tornar-se sempre mais o alimento espiritual dos membros de seu povo, a fonte para eles de uma vida de fé, de esperança e de amor, assim como uma luz para toda a humanidade". Pontifícia Comissão Bíblica, "A interpretação da 
y por iniciativa personal de su presidente, que en ese entonces era el ex Papa Joseph Alois Ratzinger.

Sobre interpretación bíblica, Ratzinger expresó el 26 de octubre del 2008 al clausurarse la XII asamblea general ordinaria del sínodo de obispos ${ }^{26}$ palabras que deberían ser profundamente analizadas:

Todos los que hemos participado en los trabajos sinodales llevamos la renovada conciencia de que la tarea prioritaria de la Iglesia, al inicio de este nuevo milenio, consiste ante todo en alimentarse de la Palabra de Dios ... Y, ya que $e l$ encuentro con la Escritura a menudo corre el riesgo de no ser "un hecho" de Iglesia, sino que está expuesto al subjetivismo y a la arbitrariedad, resulta indispensable una promoción pastoral intensa y creíble del conocimiento de la Sagrada Escritura, para anunciar, celebrar y vivir la Palabra en la comunidad cristiana, dialogando con las culturas de nuestro tiempo, poniéndose al servicio de la verdad y no de las ideologías del momento e incrementando el diálogo que Dios quiere tener con todos los hombres. ${ }^{27}$

Bíblia na Igreja", Libreria Editrice Vaticana, http://www.vatican.va/roman_ curia/congregations/cfaith/pcb_documents/rc_con_cfaith_doc_19930415_ interpretazione_po.html (consultado 05 de mayo, 2013).

${ }^{26} \mathrm{La}$ XII asamblea general ordinaria del sínodo de obispos, fue titulada: "La palabra de Dios en la vida y en la misión de la Iglesia", y se llevó a cabo del 5 al 26 de octubre de 2008. Sínodo de la Palabra, "Sínodo de la Palabra: La Palabra de Dios en la vida y en la misión de la Iglesia.", Humanitas 13:50 (2008) 415.

${ }^{27}$ Joseph Ratzinger, "Misa conclusiva de la XII asamblea general ordinaria del sínodo de los obispos", Libreria Editrice Vaticana, http://www. 
Sin embargo, interpretar la SE y luego entregar al pueblo el verdadero mensaje de Dios, liberado de las ideologías del momento, no es tan sencillo como se desearía. Heidegger, ya lo decía: "es imposible comenzar con el proceso de interpretación sin un determinado horizonte de pre-entendimiento" ${ }^{28}$ Debido a esto, surge la pregunta, “ ¿cómo puedo llegar a una comprensión que no se funde en la arbitrariedad de mis planteamientos, sino que me permita escuchar el mensaje del texto, y me brinde aquello que no tengo por mí mismo?" ${ }^{29}$ Ésta es una pregunta que hasta hoy no ha sido satisfactoriamente respondida, y planteada de distintas formas, es y ha sido el motivo de reflexión de innumerables estudiosos de la SE en el mundo.

Teólogos protestantes, como Dibelius (1883-1947) y Bultmann (1884-1976), que fueron estudiados con profundidad por los teólogos de estos últimos siglos, ante la importante pregunta planteada por Ratzinger, podrían haber asegurado que la herramienta tan buscada era el método histórico crítico (MHC). ${ }^{30}$ Sin embargo, Rudolf Bultmann,

vatican.va/holy_father/benedict_xvi/homilies/2008/documents/hf_benxvi_hom_20081026_conclusione-sinodo_sp.html (consultado 05 de mayo, 2013).

${ }^{28}$ Rodríguez, 10. También al respecto Ratzinger dice, "una objetividad pura es una abstracción absurda", véase, Joseph Ratzinger, "La interpretación bíblica en conflicto: Problemas del fundamento y orientación de la exégesis contemporánea", en Escritura e interpretación: Los fundamentos de la interpretación bíblica, ed. Luis Sánchez Navarro y Carlos Granados (Madrid: Ediciones Palabra, S.A., 2003), 29.

${ }^{29}$ Ratzinger, "La interpretación bíblica en conflicto: Problemas del fundamento y orientación de la exégesis contemporánea", 22.

${ }^{30} \mathrm{Si}$ bien es cierto el MHC tiene sus raíces junto al iluminismo. Hasel citando a Edgar Krentz y a Gerhard Maier dice al respecto: "The critical interpretative method dominant today is called the historical-critical method by its user whit its beginnings stemming from the age of rationalism 


\section{Martin Dibelius y la Pontificia comisión bíblica sobre la interpretación de la Biblia en la Iglesia, no son los únicos que tienen una respuesta a esta importante pregunta, hay} quienes han propuesto otros acercamientos y métodos hermenéuticos que pueden representar mejores alternativas que sus predecesores.

Gerhard Hasel menciona algunos de ellos junto a sus mentores y propulsores: el método del paradigma sociológico (W. Wink), el método bíblico teológico (G. Maier), el

in the eighteenth century". Gerhard Hasel, Biblical Interpretation Today (Washington, DC.: Biblical Research Institute, 1985), 6. También hay quienes ven sus orígenes mucho antes, con Aristóteles y Orígenes, Sin embargo, Salguero afirma que "Entre 1919 y 1922 aparecieron las principales obras que formularon y expusieron el Formgeschichtliche Methode. Gracias a M. Dibelius y, sobre todo, a R. Bultmann" sin los cuales sería imposible hablar del método histórico crítico. De Tuya y Salguero, 261. Gibellini por su parte argumenta que durante el Old Quest, lo que para Pereyra será parte del Segundo Quest (1953-1980), surge una nueva forma de estudio bíblico, basada en dos pilares, la teología dialéctica y un nuevo método de crítica bíblica, de la que Ludwing Schmidt, Dibelius y Bultman fueron sus iniciadores, a través del método de la historia de las formas (Formgeschichte) aplicada al Nuevo Testamento. Toda esta revolución investigativa en busca del Jesús Histórico, en la que Dibelius y Bultman jugaron un papel preponderante, darán origen al método histórico crítico, al que Zimmermann llamará, un conjunto de métodos perfectamente elaborados, entre los que destacan el método de crítica literaria de las fuentes, el método de historia de las formas y el método de historia de la redacción, que se integra mutuamente. La Old Quest disponía del método de crítica literaria de las fuentes, pero no conocía los métodos de la Formgeschichte y de la Redaktionsgeschichte, sobre los que Bultman y Dibelius tuvieron una significativa participación como ya se mencionó, hechos que, de acuerdo al criterio del autor de esta investigación, dieron origen al MHC como tal. Véase. Rosino Gibellini, La teología del siglo XX, trad. Rufino Velasco (Santander: Editorial Sal Terrae, 1998), 50; Roberto Pereyra, "Yo creo en el Jesús histórico, el Cristo de la fe", en VII simposio bíblico teológico sudamericano "Cristología", ed. Heber Pinheiro et al.(Cochabamba: Editorial UAB, 2009), 306; Heinrich Zimmermann y Gumersindo Bravo, Los métodos histórico-críticos en el Nuevo Testamento (Madrid: La Editorial La Catolica,S.A., 1969), 135-39. 
método teológico histórico (G. Hasel), el método histórico teológico (G. E. Ladd), la teología exegética (W. Kaiser), el método histórico gramático (R. Preus, J. A. Packer), el estructuralismo que hizo su ingreso a partir de 1970 (D. Patte, R. M. Polzin, R. Barthes, S. Wittig, A. M. Jhonson), entre otros. ${ }^{31}$ A esta plétora de métodos, se debe añadir las novedosas lecturas intertextuales e interdisciplinarias; así como la formulación de nuevas tendencias hermenéuticas, que han sido aplicadas a los estudios bíblicos. ${ }^{32}$ Sin embargo, todo este pluralismo de acercamientos y métodos hermenéuticos, es apreciado como un índice de riqueza por unos y despreciado por otros, a causa de la gran confusión a la que conducen. ${ }^{33}$ A esta diversidad de métodos y acercamientos, hoy en día se suma el acercamiento desconstruccionista a la SE, y aunque no es el propósito de este artículo estudiar a profundidad esta cuasi-metodología hermenéutica, se dirán algunas pocas cosas al respecto.

${ }^{31}$ Gerhard Hasel, La interpretación de la Biblia (Buenos Aires: Asociación Casa Editora Sudamericana, 1986), 92. Martínez, por su parte explica el método literalista, el método alegórico, la interpretación dogmática, la interpretación literal, el MHC entre otros, véase José M. Martínez, Hermeneutica bíblica (Barcelona: Editorial CLIE, 1984), 65-215.

${ }^{32}$ Velasco Gómez, renombrado filósofo mexicano reconoce la pluralidad hermenéutica actual, dice, "Josef Bleicher, en su libro Contemporary Hermeneutics, distingue tres tradiciones hermenéuticas: la metodológica (Dilthey y Betti); la filosófica (Gadamer y Ricoeur) y la crítica (Apel y Habermas). Por otro parte, R. J. Bernstein, en su libro La reestructuración de la teoría social y política, reconoce tres perspectivas hermenéuticas: la perspectiva lingüística (Wittgenstein y Winch), la fenomenológica (Husserl, Heidegger, Shutz) y la crítica (Horkheimer y Habermas)." Ambrosio Velasco Gómez, "La Hermenéutica en la filosofía y las ciencias sociales", en Hermenéutica analogía y discurso, ed. Martha Patricia Irigoyen Troconis (México D.F.: Universidad Nacional Autónoma de México, Instituto de Investigaciones Filológicas, 2004), 66, 65-102.

${ }^{33}$ Pontificia Comisión Bíblica, 4. 
El acercamiento desconstruccionista a la SE está construido sobre los postulados filosóficos del desaparecido francés Jacques Derrida (1930-2004), ${ }^{34}$ cuyo pensamiento es considerado la base del posmodernismo. ${ }^{35}$ Pensamientos, que intentan hacer de la palabra escrita simples neologismos que solo proponen significados, los que según él, dan lugar a oposiciones que afectan el significado original, aquél que jamás podrá ser alcanzado. ${ }^{36}$ Concepto muy claramente expresado en el análisis de la Differance hecho por

${ }^{34}$ "Jacques Derrida fue el filósofo de la desconstrucción, un filósofo de la posmodernidad. Leer al más influyente filósofo francés de los últimos tiempos es quizá más fácil que ofrecer una explicación de sus dichos... Lo que escandaliza en Derrida no es solo su condición parasitaria y de total dependencia de lo ya dicho y de lo ya escrito para sobrevivir; lo verdaderamente agitado en él es su vehemente lucha por no resolver sino por complicar". Enrique Calva, “Jacques Derrida”, Metapolitica 10:50 (2006): 55. Sobre su vida véase, Geoffrey Bennington y Jaques Derrida, Jacques Derrida (Chicago: University of Chicago Press, 1999), 15-353; Jason E. Powell, Jacques Derrida: A Biography (New York, NY: Continuum International Publishing Group, 2006), 9-255.

${ }^{35}$ Ricardo Espinoza Lolas dice: “En la actualidad es el pensamiento de Derrida el que está a la base del postmodernismo y es esencial entrar en él de modo detallado para poder situarnos filosóficamente en un diálogo serio con distintas disciplinas humanas". Ricardo Espinoza Lolas, "Derrida; En torno a la différance", Revista Observaciones Filosóficas 1:2 (2005), bajo http://www.observacionesfilosoficas.net/derridacir.html (consultado: 16 de Octubre, 2009).

${ }^{36}$ Sobre la escritura y su interpretación en Derrida véase, Ángeles Carreres, Cruzando límites: la retórica de la traducción en Jacques Derrida (Switzerland, Alemania: Peter Lang AG, 2005), 33-78; Jacques Derrida, La escritura y la diferencia, trad. Patricio Peñalver Gómez (Barcelona: Anthropos editorial del hombre, 1989), 9-408; Jacques Derrida, La diseminación, trad. José María Arancibia, 3ra ed. (Madrid: Editorial Espiral fundamentos 2007), 7-549; Jacques Derrida, La desconstrucción en las fronteras de la filosofía, trad. Patricio Peñalver Gómez (Barcelona: Ediciones Paidos Ibérica, 2010), 9-122; Faride Zerán, Desacatos al desencanto: ideas para cambiar de milenio (Santiago de Chile: LOM Ediciones, 1997), 147-60. 
Espinoza Lolas cuando dice:

... No hay ningún horizonte que permita caminar en un sentido establecido ... Lo único que queda es caminar en la vida a través de "huellas" y atenernos a ellas ... el cual se constituye en lo absolutamente diferente a cualquier camino que tenga la pretensión de ser el camino por antonomasia. El camino verdadero si queremos hablar en esos términos, solamente se impone en la medida que se camina. Y mientras esto sucede el propio camino que se va forjando en el caminar se nos convierte en simples "estelas en la mar". ${ }^{37}$

Fueron los adelantos en el campo filosófico, ${ }^{38}$ los que constituyeron la base de los estudios de Derrida, quien además se ocupó de temas tratados por autores estructuralistas

${ }^{37}$ Espinoza Lolas.

${ }^{38}$ El desarrollo filosófico se debe a personajes como: Heidegger (18891976), Roland Barthes (1915-1980), Hans-Georg Gadamer, entre otros. La influencia de los mencionados se vio en teólogos protestantes como $\mathrm{H}$. $\mathrm{H}$. Schrey, R. Bultmann y en teólogos católicos como, M. Schmaus, J. Möller, B. Welte y Karl Rahner. De los mencionados Hans-Georg Gadamer, cuya obra cumbre es: "Wahrheit und Methode Grundzügeciner philosophischen Hermeneutik" (Verdad y Método), obra considerada un clásico en la teoría hermenéutica, es considerada en el ambiente filosófico como la que da origen a la desconstrucción, sin embargo, existen diferencias entre Derrida y Gadamer, véase. Donatella Di Cesare, "Stars and Constellations: The Difference Between Gadamer and Derrida", Research in Phenomenology 34 (2004). Barthes es otro que sin lugar a dudas influyó en Derrida pues él, "examina la inestabilidad inherente a la relación entre el signo y el referente en una serie de fenómenos culturales tales como los juguetes, la publicidad, la cocina y la lucha libre". Nuevo Diccionario de Filosofia, "Barthes, Roland". Véase también, Gran Enciclopedia Rialp, 6ta ed. (Madrid: Ediciones RIALP, S.A, 1989) "Heidegger, Martín" 
en combinación con mociones procedentes de la fenomenología de Husserl, Heidegger y Hegel. Estos estudios lo llevaron a formular una nueva corriente de pensamiento a la que nombró de desconstrucción, ${ }^{39}$ que llegaría a ser trascendental para el quehacer de casi todas las ciencias humanas, incluida en ellas a la hermenéutica general, cosa que es acertadamente señalada por Cristina de Peretti cuando dice:

... jamás pensó que dicho término tendría tanto éxito, en Europa y en Estados Unidos, para designar unos giros de lectura y de escritura que, atentos al pensamiento de Derrida, inciden en lugares tan diversos como son no solo la filosofía, sino también la crítica literaria, la estética y, asimismo, la arquitectura, el derecho, el análisis de las instituciones o la reflexión política. ${ }^{40}$

También la hermenéutica bíblica moderna fue afectada por la desconstrucción ${ }^{41}$ corriente que en los estudios

${ }^{39}$ Desconstrucción es el término que mejor representa en español la palabra dé-construction que se usa por primera vez en francés, en el libro De la Gramatología publicado el año 1967. La misma hace parte de una frase creada para tratar de dar el significado al neologismo francés formado por dos sustantivos, dé, y constructión. Apartándose así de lo más lógico, aún en francés, la unión del prefijo de con el sustantivo mencionado. Véase, Jacques Derrida, De la Grammatologie (Paris: Les Éditions de Minuit, 1967), 21; Jacques Derrida, De la gramatología, trad. Oscar del Barco y Conrado Cereti, 8va ed. (México D.F.: Siglo Veintiuno Editores, 2005), 16.

${ }^{40}$ Cristina de Peretti, "Deconstrucción", en Diccionario interdisciplinar de hermenéutica, ed. Andrés Ortiz-Osés y Patxi Lanceros (Bilbao: Publicaciones de la Universidad de Deusto, 2006), 97.

${ }^{41}$ Javier Higuero señala al respecto, “La estrategia deconstruccionista, tal como la proponen estos críticos, no solo es aplicable primordialmente a escritos teológicos, sino que también constituye una alternativa positiva a concepciones 
bíblicos-teológicos no es considerado un método hermenéutico, pero que puede ser considerado como una estrategia ${ }^{42} \mathrm{o}$ un acercamiento. $\mathrm{Y}$ son al parecer estos conceptos hermenéuticos filosóficos los que conducen a Quezada del Río a decir que,

. . la Biblia es maestra, más que de actitudes o creencias, de interpretación y actualización. Y una característica de sus reinterpretaciones reside en que son plurales y soportan la tensión, por lo que la interpretación - actualización - "debe necesariamente ser plural". ${ }^{43}$

\section{Son estas presuposiciones filosóficas ${ }^{44}$-descons-}

mitológicas o humanistas", para luego continuar diciendo que "G. Douglas Atkins, en Reading Deconstruction. Deconstructive Reading, ha señalado que el enfoque deconstructor ha sido utilizado con éxito en el estudio tanto de tratados de exégesis bíblica como de pensamiento teológico". Francisco Javier Higuero, Estrategias deconstructoras en la narrativa de Jiménez Lozano (Rock Hill, SC: Spanish Literature Publications Company, 2000), 9. Sobre la desconstrucción y su influencia en la Teología véase, John D. Caputo, The Prayers and Tears of Jacques Derrida: Religion Without Religion (Bloomington, Indiana: Indiana University Press, 1997), 35-36; Brian D. Ingraffia, Postmodern theory and biblical theology: vanquishing God's shadow (New York: Cambridge University Press, 1995), 165-75; Stephen D. Moore, Post Structuralism and the New Testament: Derrida and Foucault at the Foot of the Cross (Mineapolis, MN: Fortress Press, 1994), 11-82. También en el quehacer adventista esta nueva tendencia hermenéutica esta hacienda su ingreso. Véase, Fernando L. Canale, "Deconstrucción y teología: una propuesta metodológica", DavarLogos 1:1 (2002) 3-26.

${ }^{42}$ Peretti, 98.

${ }^{43} J a v i e r$ Quezada del Río, “¿Cómo puede ser la Biblia el alma de la teología?", Theologica Xaveriana 59: 167 (2009), bajohttp://redalyc.uaemex. $\mathrm{mx} / \mathrm{src} /$ inicio/ArtPdfRed.jsp?iCve=191014785006 (consultado: 10 de noviembre, 2010).

${ }^{44}$ Canale advierte que son de dos tipos las presuposiciones que 


\section{truccionistas - las que dan origen a lecturas hermenéu- ticas posmodernas, ${ }^{45}$ que ven la verdad como un asunto relativo, ${ }^{46}$ y que al respecto Timm dice:}

juegan un rol importante al interpretar el texto bíblico, las presuposiciones hermenéuticas y las presuposiciones metodológicas". Define a las presuposiciones hermenéuticas, como correspondiendo a aquella que llaman los filósofos y teólogos, de axiomas y principios. Son estas presuposiciones hermenéuticas el motivo de esta investigación. Fernando L. Canale, A Hermeneutical View of Biblical Revelation (Berrien Springs, MI: Andrews University Press, 2000), 93.

${ }^{45}$ Existe una marcada diferencia entre la hermenéutica antigua y el procedimiento exegético antiguo con el actual pues, como lo indica Trevijano, en tiempos antiguos la distinción entre las interpretaciones radicaba en el sentido literal o espiritual que se le daba al texto, mientras que en la actualidad estas conclusiones "chocan con las conclusiones de las ciencias del lenguaje y de las hermenéuticas filosóficas, que afirman la polisemia en los textos escritos". Trevijano Etcheverria, 23.

${ }^{46 "}$ Muchos exponentes de la nueva hermenéutica sobrepasan el límite. Ellos argumentan que toda vez que la interpretación de las personas difiere en alguna medida de las de otras, no se puede hablar legítimamente del significado del texto (como si esto fuera algo objetivo). Ellos dicen que el significado no está en el texto sino en los lectores, los intérpretes, del texto. Si las diferentes interpretaciones son legítimas, entonces no se puede hablar de la interpretación correcta, o la interpretación verdadera; ellos piensan que tales expresiones terminan en afirmaciones de preferencia personal. Si ninguna interpretación en particular es correcta, entonces todas las interpretaciones son erróneas (lo cual conduce al nihilismo hermenéutico conocido como "desconstruccionismo"), o todas son igualmente "correctas"; p. ej. todas son buenas o malas en la medida que satisfacen o cumplen con las necesidades de una persona en particular, o comunidad, o cultura; o simplemente satisface cierto criterio arbitrario... Alineada con el poderoso respeto contemporáneo que la cultura occidental le asigna al pluralismo, esta nueva hermenéutica considera que ninguna interpretación es inválida excepto aquella que declara ser la correcta haciendo a las otras incorrectas". Donald A. Carson, Sección acercándonos a la Biblia de Nuevo comentario bíblico: siglo veintiuno, eds. James Bartley, José Luis Martínez, y Rubén O. Zorzoli (El Paso, Texas: Casa Bautista de Publicaciones, 1999), 23. 


\begin{abstract}
Al cambiar el foco (pasar de las Escrituras al lector) los posmodernos abren el texto bíblico a una variedad de interpretaciones subjetivas, todas igualmente válidas. Consecuentemente, ya no hay una clara y consistente Palabra de Dios, sino muchas palabras en conflicto, supuestamente atribuidas a él. ${ }^{47}$
\end{abstract}

Como ya se puede percibir, estudiar la SE y hacer que los resultados de este estudio sean considerados universalmente válidos en el actual mundo posmoderno, es un asunto que al parecer, es imposible. Debido a ello, se puede afirmar que el teólogo y exégeta de hoy, se enfrenta cada día a nuevas presuposiciones y con ellas a nuevos acercamientos y métodos hermenéuticos que, aunque no siempre deben ser usados, necesitan ser conocidos y evaluados.

Lo mencionado hasta aquí, da lugar a innumerables preguntas relacionadas al asunto hermenéutico de la SE, que ciertamente serían imposibles de responder en su totalidad y de forma plena, pero que se hace necesario abordar desde la particular perspectiva de la Iglesia Adventista del Séptimo Día (IASD).

\title{
La hermenéutica bíblica en el adventismo actual
}

Aunque aquí no se pretende profundizar en el estudio de todos los métodos y acercamientos hermenéuticos que tratan de incursionar en la IASD, este artículo se propone identificar la realidad hermenéutica entre sus círculos

${ }^{47}$ Alberto R. Timm, “Las Escrituras y la experiencia”, Ministerio Adventista, septiembre-octubre 2009, 31. 
académicos, pues se cree que ella es determinante para el futuro de la IASD, pues como Lince Campillo señala:

Muchos autores han llegado a considerar que el porvenir de las humanidades depende de saber interpretar correctamente las huellas humanas, ya sea mediante el estudio de sus obras culturales, artísticas, documentos históricos y cualquier expresión en donde se encuentre impreso su espíritu. ${ }^{48}$

Parafraseando esta frase, se puede decir que el futuro del IASD, se encuentra estrechamente ligado a la hermenéutica, ${ }^{49}$ es decir, al saber interpretar correctamente su desarrollo, obras, documentos históricos y principalmente la Sagrada Escritura, pues como se dijo, la Biblia debe ser interpretada. Una tarea del cristianismo y, por lo tanto, una tarea de la IASD es realizar con éxito la tarea hermenéutica, sin embargo, los desafíos que se debe sortear para cumplir esta misión, son cada día mayores. Aquí

${ }^{48}$ Rosa María Lince Campillo, Hermenéutica: arte y ciencia de la interpretación (México D.F.: Universidad Nacional Autónoma de México, 2009), 19.

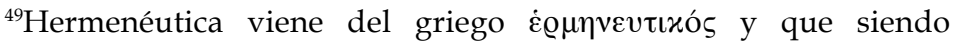
un sustantivo encuentra su significado en verbos, como: interpretar, comunicar, explicar, anunciar, proclamar, aclarar esclarecer e iluminar el entendimiento. Lince Campillo define a la palabra de la siguiente manera: Hermenéutica es, "exponer un anuncio que previamente se ha escuchado como mensaje, en pocas palabras dar a conocer algo. En este sentido, es un ejercicio que transforma porque nos enseña a recibir mensajes y a entender juicios. En esta dimensión práctica puede considerarse a la metodología hermenéutica como un arte de la interpretación y una teoría de la comunicación". Ibíd., 35, 36. 
de forma sucinta se extrae de la literatura adventista ${ }^{50}$ los mayores problemas y soluciones relacionados con el quehacer hermenéutico que ella enfrenta en la actualidad para exponerlos de forma puntual.

\section{Problemas que se presentan}

Los grandes problemas que enfrenta la hermenéutica en la IASD, giran en torno a la fuente de las presuposiciones que gobiernan la mente del investigador y de los métodos que se originan en base a ellas. Dejar las presuposiciones de la fe provistas por la revelación escrita, y usar las presuposiciones del método científico evolucionista para interpretar la Escritura, ${ }^{51}$ es una constante entre algunos de los actuales estudiosos bíblicos adventistas, esto ha conducido a un reconocido pluralismo teológico actual ${ }^{52}$ que ha dado

${ }^{50}$ Todos los autores revisados reconocen que existen dificultades en la hermenéutica de la iglesia, sin embargo, no siempre su visión es la misma, revisar sus declaraciones puede ayudar a comprender, de forma global, la condición hermenéutica en la Iglesia Adventista del Séptimo Día.

${ }^{51}$ Para él este tipo de estudio da como resultado una ciencia errática, que no tiene valor ni posibilidad de entregar la verdad, razón por la cual él señala que "el adventismo debería estudiar seriamente el método a través del cual llega a sus conclusiones", para luego señalar que "es imperativo que la metodología teológica y sus condiciones material, teleológica y hermenéutica no sean extraídas de otras escuelas teológicas", sino únicamente de la Biblia.

${ }^{52}$ Para Koranteng-Pipim, no habla de la izquierda liberal y la derecha independiente, al respecto señala que "en lo que se refiere al estilo de vida o conducta, los liberales enfatizan el amor, la aceptación y la inclusividad. Los independientes resaltan la ley, el perfeccionismo y la unicidad". Samuel Koranteng-Pipim, Recibiendo la palabra ¿cómo afectan a nuestra fe los nuevos enfoques bíblicos?, trad. David P. Gullón (Buenos Aires: Asociación Casa Editora Sudamericana, 1997), 29. Sin embargo, hoy se reconoce 4 líneas por las cuales se mueve el adventismo, el adventismo evangélico, el adventismo progresita, el adventismo histórico y el adventismo madre. 
lugar al cuestionamiento de las creencias distintivas de la IASD, obra que debería ser el quehacer de los críticos externos, pero lamentablemente se debe reconocer que hoy existe una crítica interna ${ }^{53}$ más recalcitrante que la externa la que, a decir verdad, es casi imperceptible.

Debido a ello se puede afirmar que de forma involuntaria, pero evidentemente práctica, el quehacer interpretativo de la IASD se está apartando paulatinamente de su origen bíblico al tomar las presuposiciones modernas y posmodernas para interpretar la Escritura. ${ }^{54}$ Todos estos hechos muestran que la IASD, en la actualidad, no solo enfrenta al Método Histórico Crítico (MHC) y sus presuposiciones, sino que a una plétora de novedosos métodos hermenéuticos ${ }^{55}$ que están haciendo ingreso en su seno casi

Véase, Kenneth Wood, "The Mother of us All: Mainstream Adventist", Adventist Today 2:1 (1994) 4-5. Los artículos que hablan sobre las otras cuatro líneas del adventismo se pueden revisar en la misma revista.

${ }^{53}$ Koranteng-Pipim dice al respecto: "se están cuestionando desde adentro las doctrinas teológicas más distintivas". Koranteng-Pipim, 29.

${ }^{54}$ Frank Hasel reconoce este hecho y dice al respecto, "Nuestras presuposiciones e interpretaciones previas precisan modificarse y amoldarse según el texto de las Sagradas Escrituras y mantenerse bajo el control de la propia Biblia. El texto bíblico debe tener prioridad sobre el intérprete". Frank M. Hasel, "Presuposiciones en la interpretación de las Sagradas Escrituras", en Entender las Sagradas Escrituras: El enfoque adventista, ed. George W. Reid, Clásicos del adventismo (Florida: Asociación Publicadora Interamericana, 2009), 34 .

${ }^{55}$ Gerhard Hasel, uno de los eruditos adventistas a quien se le debe mucho por su incansable esfuerzo por contrarrestar el ataque contra la Biblia, llevado a cabo de forma sistemática por el método histórico crítico, ya reconocía la llegada de nuevos métodos de interpretación bíblica, con los que tendría que lidiar el adventismo, sin embargo, a los que él reconocía, hoy en día, se añaden nuevos métodos y nuevas hermenéuticas, como la desconstruccionista, la hermenéutica de género, la feminista, y otras. Véase, Hasel, La interpretación de la Biblia, 92. 
imperceptiblemente. Por lo tanto, la polarización teológica, también origina una mayor polarización hermenéutica, de la que lo origina.

Otro de los problemas directamente relacionados con la hermenéutica es la comprensión que la IASD tiene del proceso de revelación e inspiración, ${ }^{56}$ tema que, según Canale, debe ser profundamente evaluado, pues según él, este influye de forma determinante en la interpretación bíblica, a través "de los principios hermenéuticos que se derivan de ella" ${ }^{57}$ Por otro lado, Canale ve que la pluralidad hermenéutica, existente en la IASD, radica en la pérdida que el adventismo actual tiene del proyecto teológico adventista pionero y en la práctica común entre muchos de los pastores y líderes de la Iglesia de experimentar "con ideas teológicas nuevas pocas veces derivadas de la Biblia... tomadas de libros de teología de otras denominaciones y adaptadas para el uso del adventismo". ${ }^{58}$

La hermenéutica adventista ha enfrentado desafíos en cada período de su historia, sin embargo, en las últimas décadas estas se han incrementado, se pueden mencionar de forma puntual a: 1) la aceptación de versiones modificadas del método histórico-crítico, 2) la introducción del llamado principio apotelesmático de interpretación profética, 3) lec-

${ }^{56}$ Canale afirma: que "los adventistas no están unidos en su interpretación del asunto fundamental de la RI" y que los tres puntos de vista más comunes entre ellos fueron formulados en base a ideas filosóficas y no bíblicas. Fernando Canale, "Revelación e inspiración", en Entender las Sagradas Escrituras: El enfoque adventista, ed. George W. Reid, Clásicos del adventismo (Florida: Asociación Publicadora Interamericana, 2009), 92.

${ }^{57}$ Ibíd., 87.

${ }^{58}$ Fernando L. Canale, "Completando la teología adventista I: La tarea teológica en la vida de la iglesia - Parte I”, Davar-Logos 6:1 (2007) 58. 
turas futuristas del Daniel 12 y 4 ) elementos hermenéuticos posmodernos. ${ }^{59}$

Por la importancia que tiene, es necesario enfatizar que el posmodernismo representa un gran desafío para el quehacer hermenéutico de la IASD. ${ }^{60}$ Pues como se dijo anteriormente, el teólogo y exégeta de hoy, se enfrenta cada día a nuevas presuposiciones y con ellas a nuevos acercamientos y métodos hermenéuticos, que aunque no siempre deben ser usados, necesitan ser conocidos y evaluados.

Todo lo mencionado hasta aquí, obliga a que se hable de la hermenéutica bíblica en plural en el seno de la IASD, pues son diversas las formas cómo la sociedad cree poder acercarse al texto bíblico, ${ }^{61}$ y esta es la corriente que está

${ }^{59} \mathrm{Timm}$ desarrolla de forma sucinta pero clara el desarrollo histórico de la hermenéutica de la IASD, y señala de forma clara que son cuatro los retos contemporáneos que el adventismo tiene en relación a la interpretación bíblica. Alberto R. Timm, "Antecedentes históricos de la interpretación adventista de la Biblia", en Entender las Sagradas Escrituras: El enfoque adventista, ed. George W. Reid, Clasicos del Adventismo (Florida: Asociación Publicadora Interamericana, 2009), 15, 16.

${ }^{60} \mathrm{Timm}$ dice al respecto que "Al cambiar el foco (pasar de las Escrituras al lector) los posmodernos abren el texto bíblico a una variedad de interpretaciones subjetivas, todas igualmente válidas. Consecuentemente, ya no hay una clara y consistente Palabra de Dios, sino muchas palabras en conflicto, supuestamente atribuidas a él". Timm, "Las Escrituras y la experiencia," 31.

${ }^{61} \mathrm{Al}$ respecto dice Davidson: "Los ejemplos principales incluyen la hermenéutica filosófica... las hermenéuticas sociocrítica, incluyendo la crítica sociológica (Gottwald), de la liberación (Gutierrez) y la hermenéutica feminista (Trible), la "critica de la recepción" [reader-response] (Mcknight); y el deconstruccionismo (Derrida)"; debido a todo ello dirá Davidson "Ya no existe un significado obvio y normativo de las Escrituras; sino una lectura feminista, una lectura desde el punto de vista de la raza negra, una lectura asiática, una lectura luterana". Richard M. Davidson, "Interpretación bíblica", en Tratado de teología Adventista del Séptimo Día, ed. Aldo D. Orrego(Buenos Aires: Asociación Casa Editora Sudamericana, 2009), 108. 
siguiendo la hermenéutica adventista. Del mismo modo, el crecimiento de la Iglesia, por contradictorio que parezca, también se ha convertido en un desafío y un peligro para la hermenéutica adventista, ${ }^{62}$ pues el ingreso masivo y poco controlado de feligreses alrededor del mundo, produce una crisis en la identidad de la Iglesia y, por consiguiente, una crisis en la metodología hermenéutica que ella practica.

Ángel Manuel Rodríguez, un reconocido erudito adventista, reconoce que en la actualidad la enseñanza doctrinal teológica, la identidad y la unidad de la Iglesia se encuentran amenazadas, y señala nueve problemas relacionados al quehacer hermenéutico ${ }^{63}$ que enfrenta y enfrentará la IASD en los siguientes años. Estos puntos necesitan ser evaluados, reconociendo que todo lo que la Iglesia experimenta hoy en día muestra lo vulnerable que

${ }^{62}$ Koranteng-Pipim señala que el ingreso del liberalismo está acompañado por el ingreso de feligreses jóvenes no conocedores de la larga tradición adventista de más de 150 años. Véase, Koranteng-Pipim, 18,19 .

${ }^{63}$ Los nueve problemas relacionados al quehacer hermenéutico de la IASD que Rodríguez menciona son: 1) La filosofía del crecimiento de iglesia. 2) El peligro de no tener conciencia histórica de la Iglesia. 3) El peligro de desarrollar teologías regionales por ser una iglesia mundial y diversa. 4) El surgimiento de nuevos grupos progresistas que han desafiado las posturas de la Iglesia en cuanto a los temas sociales y científicos. 5) El peligro de que los creyentes encuentren "nueva luz", como fruto de su estudio personal de la Biblia, especialmente de los textos difíciles. 6) Los problemas en la escatología e interpretación profética. 7) La persistencia de la idea congregacionalista en un grupo de creyentes. 8) Las diferentes liturgias en diferentes partes del mundo. 9) La tendencia en algunos sectores de la Iglesia que abogan por el perfeccionismo, para ser salvo y otras que dicen que Jesús ya lo hizo todo. Ángel Manuel Rodríguez, "Polarización teológica: causas y tendencias", Ministerio adventista, septiembre - octubre 2011, 13-19. 
ella es, frente a los ataques del enemigo de $\operatorname{Dios}^{64}$ y lo fácil que puede apartarse de la verdad.

\section{Soluciones propuestas}

Las soluciones que se proponen, a los problemas hermenéuticos que enfrenta la IASD en la actualidad, están directamente relacionados con las causas que los autores ven para esta dificultad, así por ejemplo Rodríguez dirá que cuando la polarización es extrema, la solución pasa a ser un asunto administrativo. ${ }^{65}$

Por otro lado, hay quienes ven en las amenazas, oportunidades, por ejemplo, se dijo que el posmodernismo representa un problema para el quehacer hermenéutico, pero según Gulley, esta es también una oportunidad. ${ }^{66}$ Por su parte, Davidson dirá que la solución a la realidad hermenéutica adventista está en ver a la Biblia como el libro que ella reclama ser, la palabra de Dios. ${ }^{67}$

${ }^{64}$ Koranteng-Pipim dice, "Ahora que el liberalismo ha llegado a estar vigente dentro de nuestra iglesia, percibimos cuan vulnerables podemos ser a los asaltos de Satanás". Koranteng-Pipim, 227.

${ }^{65}$ Dice él: “Si la situación se vuelve intolerable, ya no está en las manos de los teólogos, sino en la de los administradores de la iglesia". Rodríguez, "Polarización teológica: causas y tendencias," 19.

${ }^{66}$ Gulley dice: “En su mayoría, a los posmodernos les falta la fibra espiritual que trae una paz y una realización duraderas. A pesar de todo el relativismo y la aversión a los sistemas y a la objetividad, a los absolutos y a lo trascendente, las necesidades de los posmodernos claman por las mismas cosas que han rechazado. De nuevo vemos aquí que no pueden vivir de sus propias teorías". Norman R. Gulley, Cristo viene: Un enfoque cristocéntrico de los eventos de los últimos días, trad. David P. Gullón (Buenos Aires: Asociación Casa Editora Sudamericana, 2003), 39.

${ }^{67}$ Davidson, 73-75. 
Por otro lado, para Canale, es necesario que la IASD evalúe (revise) la función del santuario y los otros tres hitos de la fe adventista, ${ }^{68}$ pues para él estos son los principios macrohermenéuticos ${ }^{69}$ sobre los cuales, se construyó y se debería continuar construyendo la teología adventista. También él dirá que es necesario estudiar, con mayor detenimiento, el tema de la revelación e inspiración, pues son fundamentales para la hermenéutica adventista. ${ }^{70}$ Finalmente, Canale propuso el uso de la desconstrucción ${ }^{71}$ como

${ }^{68}$ Elena G. de White señala: “El tiempo transcurrido en 1844 fue un período de grandes eventos, que abrió ante nuestros ojos asombrados la purificación del santuario que se llevaba a cabo en el cielo, y tuvo una decidida relación con el pueblo de Dios sobre la tierra; [también con] los mensajes del primero y segundo ángeles y con el tercero, y desplegó el estandarte en el cual estaba inscrito: "Los mandamientos de Dios y la fe de Jesús". Uno de los hitos de este mensaje fue el templo de Dios, visto en el cielo por su pueblo amante de la verdad, y el arca que contenía la ley de Dios. La luz del día de reposo del cuarto mandamiento resplandeció con sus fuertes rayos en el camino de los transgresores de la ley divina. La no inmortalidad de los malvados es un antiguo hito. No puedo recordar nada más que pueda colocarse bajo el título de los antiguos hitos. Elena G. de White, Eventos de los últimos días, trad. Néstor Alberro, 2da ed. (Buenos Aires:: Asociación Casa Editora Sudamericana, 1990), 45, 46.

${ }^{69}$ Canale afirma que: "el conocimiento del santuario y el cumplimiento profético llegaron a ser las presuposiciones macrohermenéuticas que influyeron en la teología adventista por más de un siglo". Fernando Canale, Creación, evolución y teología: una introducción a los métodos científico y teológico, trad. Claudia Blath (Entre Ríos, Argentina: Editorial Universidad Adventista del Plata, 2009), 125. Estos argumentos dan lugar a que Armenteros señale que uno de los mayores aportes de este material "está relacionado con la condición hermenéutica". Víctor Armenteros y Esther Sánchez, recensión de, Creación, evolución y teología: una introducción a los métodos científico y teológico, por Fernando Canale, Enfoques 21:1-2 (2009): 117-27.

${ }^{70}$ Canale dice al respecto, "Nuestra comprensión de la revelación e inspiración se convierte en una suposición necesaria para nuestra hermenéutica de las Sagradas Escrituras y de su teología". Canale, "Revelación e inspiración”, 60. 
una herramienta filosófica y metodológica en el quehacer de la hermenéutica de la IASD, alternativa cuyas repercusiones producirían un daño mayor al quehacer hermenéutico en la IASD, pues llevarían al hermeneuta adventista, muy lejos de las más evidentes presuposiciones bíblicas. ${ }^{72}$

Frank Hasel, habla de "una mentalidad abierta embutida de una disposición de aprender, una mentalidad receptiva al mensaje y al contenido objeto de estudio", ${ }^{73}$ él continúa diciendo que, además, el hermeneuta de la IASD debe "acercarse al texto bíblico con una disposición a abrir las convicciones fundamentales al poder transformador del Espíritu Santo". ${ }^{74}$ También él, junto a otros ya mencionados, abogan por tratar a la Biblia como palabra de Dios, confiable y autoritativa, también cree que para una correcta interpretación de las Escrituras se debe vivir bajo sus mandatos y normas, en una correcta relación con Dios. ${ }^{75}$

También se dirá que aunque hay quienes abogan por un pluralismo teológico y hermenéutico, la IASD no puede inclinarse fácilmente por esta opción, pues ello podría traer resultados catastróficos sobre las creencias y prácticas de los adventistas. ${ }^{76}$ Finalmente se cree junto a Correa, que no

${ }^{71}$ Canale, “Deconstrucción y teología: una propuesta metodológica”, 3-26.

${ }^{72}$ Véase, Benjamin Rojas Yauri, "Presuposiciones del acercamiento desconstruccionista derridiano y su influencia en la aproximación al texto bíblico" (Tesis de Maestría, Universidad Peruana Unión, 2012), 132-68.

${ }^{73} \mathrm{Hasel}$, "Presuposiciones en la interpretación de las Sagradas Escrituras", 41.

${ }^{74}$ Ibid., 42.

${ }^{75}$ Ibíd., 53.

${ }^{76}$ Koranteng-Pipim dice, “Aceptar un sistema de interpretación múltiple (pluralismo hermenéutico) requiere que uno asuma que no hay 
existe un método perfecto de interpretación bíblica, pero que sí existen métodos mejores y más respetuosos que, bien usados, conducen a un mejor entendimiento del texto bíblico. ${ }^{77}$ Por lo tanto, la evaluación de estos métodos -los más respetuosos del texto bíblico- y la búsqueda y selección de las herramientas hermenéuticas, que ellos proporcionan, es actualmente una tarea obligatoria e imperiosa que debe llevar a cabo la IASD, solo así, ella podrá transitar en este nuevo siglo, con la seguridad de que su comprensión -interpretación- de la Sagrada Escritura, es una que no está guiada -fundamentada- por la filosofía del momento.

\section{Conclusiones}

La más importante conclusión de este estudio puede ser parafraseada en base a algunos escritos de Timm, donde señala, que la Iglesia hoy vive uno de los momentos más críticos de su historia, que para el autor de este documento, se trata de una crisis hermenéutica. Crisis en la cual la tendencia es seguir la corriente popular y mayoritaria, donde la pluralidad y la tolerancia prevalecen. Luego, también parafraseando a Timm uno se pregunta, ¿Será que la Iglesia conseguirá enfrentar esta crisis hermenéutica? ${ }^{78}$ Aunque el

armonía o unidad fundamental en la Escritura, que la Escritura puede ser interpretada de muchas maneras diferentes pero, a pesar de todo, igualmente verdaderas". Koranteng-Pipim, 185.

${ }^{77}$ Correa dice: "existen tantos métodos para hacer teología como teólogos existen". S. Teófilo Correa, "Intertextualidad y exégesis intrabíblica: ¿dos caras de la misma moneda? breve análisis de las presuposiciones metodológicas", DavarLogos 5:1 (2006) 2. Sin embargo, también reconoce que existen métodos que tienen "una aproximación más respetuosa con el texto, valorando su autoridad y originalidad en la misma Biblia". Ibíd., 11.

${ }^{78}$ Las ideas para esta paráfrasis fueron tomadas de Alberto R. Timm, 
cuadro parezca sombrío, las propuestas para solucionar esta crisis están dadas, es probable que no sean concluyentes, sin embargo, ellas giran en un mismo sentido y, en este punto, no se equivocan, el investigador adventista no debe apartarse de la Biblia y sus presuposiciones hermenéuticas, pues es notorio que en algunos casos la investigación bíblica adventista ha dejado de ser bíblica y ha pasado a ser social, positivista o filosófica. ${ }^{79}$

“¿Podemos aún ser considerados el “Pueblo de la Biblia?", Revista Adventista, julio 2003, 8 .

${ }^{79}$ Aunque se debe reconocer que existe una filosofía bíblica. Lo que se transmite en esta frase es la idea de que fueron los presupuestos filosóficos griegos, modernos o posmodernos los que sirvieron de base para la interpretación bíblica en ciertos sectores del adventismo. 